\title{
Milk Fat Content Measurement by a Simple UV Spectrophotometric Method: An Alternative Screening Method
}

\author{
D. O. Forcato, ${ }^{1}$ M. P. Carmine,${ }^{2}$ G. E. Echeverría,${ }^{3}$ R. P. Pécora,${ }^{2}$ and S. C. Kivatinitz ${ }^{1}$ \\ ${ }^{1}$ Departamento de Química Biológica-CIQUIBIC, Facultad de Ciencias Químicas, Universidad Nacional de Córdoba, Argentina \\ ${ }^{2}$ Departamento de Química Industrial y Aplicada, Cátedra de Bromatología y Toxicología, Facultad de Ciencias Exactas, \\ Físicas y Naturales, Universidad Nacional de Córdoba and Departamento de Protección de Alimentos, \\ Ministerio de la Producción y Trabajo, Gobierno de Córdoba, Argentina \\ ${ }^{3}$ Fundación Escuela Superior Integral de Lechería (FUNESIL), Villa María, Córdoba, Argentina
}

\begin{abstract}
We developed a simple microtechnique to measure lipids in milk by UV spectrophotometry. This technique is based upon the property of fatty acids to absorb UV light proportional to their concentration. Samples of powdered or fluid milk (30 or $60 \mu \mathrm{L}$ ) were added to $3 \mathrm{~mL}$ of analytic grade ethanol and stored at $-20^{\circ} \mathrm{C}$ for at least $1 \mathrm{~h}$. This procedure precipitates proteins and hydrophobic peptides that interfere with UV measurement. Sample absorbances are then measured at $208 \mathrm{~nm}$ in an UV-Vis spectrophotometer. This technique correlated very well against Milko-Scan, a device that measures milk fat by IR spectroscopy, with an $r^{2}>0.982$. Accuracy and precision, evaluated by recovery and replicate assays, are also very acceptable. This method is suitable as a fast, cost-effective alternative screening method to estimate milk fat content in small samples without prior lipid extraction.
\end{abstract}

(Key words: milk fat, UV-spectrophotometry, lipid measurement)

Abbreviation key: \%RSD = percentage of relative standard deviation.

\section{INTRODUCTION}

Milk fat measurement is a common task in the dairy industry, because milk fat content is one factor that determines milk price and is necessary to know for casein/fat ratio normalization. It is also important for the dairyman to know milk fat content exactly: discrepancies in the results of milk fat tests (usually performed in the dairy industrial plant) have economic relevance. In addition, a low milk fat content could indicate the existence of animal health deficiencies.

Received July 28, 2004.

Accepted October 4, 2004.

Corresponding author: S. C. Kivatinitz; e-mail: skivat@dqb.fcq. unc.edu.ar.
This is all the more important in Argentina, where exact milk fat contents for the different kind of milk are established by Federal regulations for both fluid and powdered milk.

Several techniques that measure milk fat content have been used and improved over time. The RöseGottlieb reference method and the Gerber butyrometric method are the most extended and traditional ones (International Dairy Federation, 1987, 1991), but they are labor and time consuming, and employ several reactives (some of them dangerous) and specific equipment. In addition, these methods are not suitable for a large number of samples. Other methods involve milk fat extraction with organic solvents before measurement, a time consuming procedure that involves several manual operations and high intraassay and interassay error. These methods usually make use of large amounts of chlorinated or nonchlorinated solvents (Smedes, 1999; Application Note, Dionex 345, 1999), which are expensive and produce adverse effects on the environment. The dairy industry makes use of several automated methods specially developed for it (Wüst and Rudzik, 2003). These procedures have proved to be precise and accurate, allowing industries to measure several other milk components in addition to fat, and are capable of multiple-sample assay, but they still require specific devices and are very expensive for the budgets of non-industrial laboratories.

Food laboratories, which seldom perform milk fat measurements, need cost-effective methods demanding only regular laboratory equipment. Here we present a fast, cost-effective, and reproducible method for milk fat measurement in fluid and powdered milk, which makes use of the UV adsorption properties of lipids, uses ethanol as the sole solvent, and only requires a UV spectrophotometer.

\section{MATERIALS AND METHODS}

\section{Milk Samples}

Whole milk (3\% milk fat), skimmed milk (1.5\% milk fat), defatted milk (0.01 and $0.04 \%$ milk fat), milk 
Table 1. Correlation analysis between Milko-Scan and UV absorbance at 208-nm measurements performed in different laboratories.

\begin{tabular}{llll}
\hline & $\mathrm{r}^{2}$ & $\mathrm{n}$ & $P$ \\
\hline Laboratory 1 & & & \\
$1^{1}$ & 0.990 & 14 & $<0.001$ \\
$2^{1}$ & 0.982 & 14 & $<0.001$ \\
$3^{2}$ & 0.982 & 14 & $<0.001$ \\
Laboratory 2 & & & $<0.001$ \\
$1^{1}$ & 0.983 & 12 & $<0.001$ \\
$2^{2}$ & 0.992 & 12 & \\
\hline${ }^{1} 30-\mu$ L sample. & & & \\
${ }^{2} 60$ - $\mu$ L sample. & & &
\end{tabular}

cream (44\% milk fat), powdered milk (3\% milk fat), and azidiol ( $50 \mu \mathrm{L} / 10 \mathrm{~mL}$ of milk; milk preservative on the basis of sodium azide and chloramphenicol kindly provided by FUNESIL, Villa María, Córdoba, Argentina) were provided by a local dairy plant (La Lácteo S.A., Córdoba, Argentina). Samples with different fat content were prepared mixing proper volumes of whole, skimmed, and defatted milk. Samples containing $>3 \%$ of fat were prepared by adding milk cream to $3 \%$ fat milk. Samples were preserved with azidiol until fat measurement. Samples were divided into 3 subsamples and measured with 2 different Milko-Scan equipments from different laboratories (kindly provided by La Lácteo SRL and FUNESIL, Villa María, Córdoba, Argentina) and by the UV method. Calibration of both devices was performed bimonthly using 11 samples certified by the Argentinean official body INTI/CITIL (Buenos Aires, Argentina). Daily controls were performed using 2 samples of 3 and $4 \%$ of milk fat measured by the Mojonnier method.

\section{Procedure}

Milk (30 or $60 \mu \mathrm{L}$ ) was added to $3 \mathrm{~mL}$ of absolute ethanol (Ciccarelli, Argentina) at $-20^{\circ} \mathrm{C}$. All vials were hermetically capped and stored for $1 \mathrm{~h}$ at $-20^{\circ} \mathrm{C}$. This procedure allows the precipitation of proteins and hydrophobic peptides that interfere with UV measurement. Samples were centrifuged at 13,000 rpm for 15 min and allowed to reach room temperature. Aliquots of the supernatants were directly transferred to a $1-\mathrm{cm}$ path, and samples were measured at UV wavelengths (spectral range, 200 to $300 \mathrm{~nm}$ ).

\section{RESULTS AND DISCUSSION}

\section{Calibration Curves at Different UV Wavelength}

The spectral curves of several milk samples were analyzed. Figure 1A shows that milk samples have a wide absorption peak in the range of $\sim 220$ to $240 \mathrm{~nm}$
$\mathbf{A}$

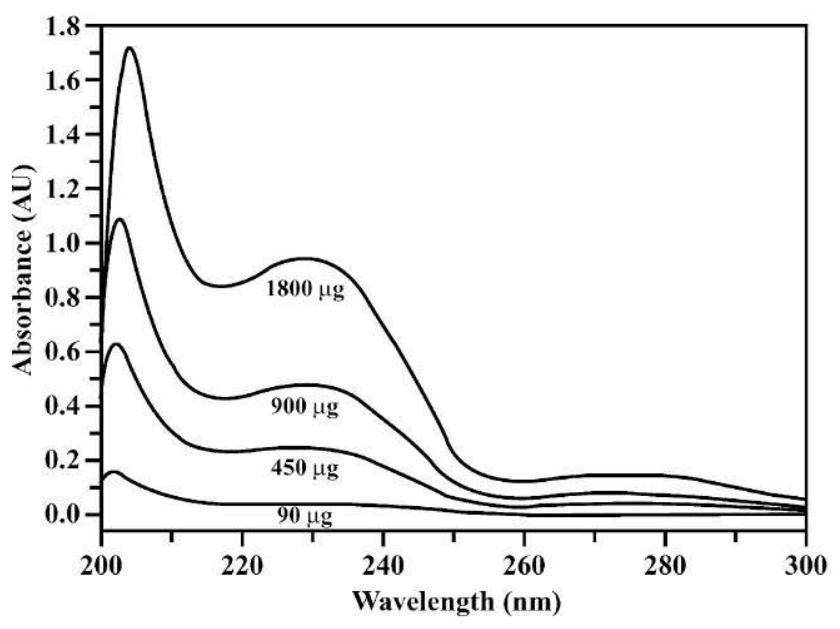

B

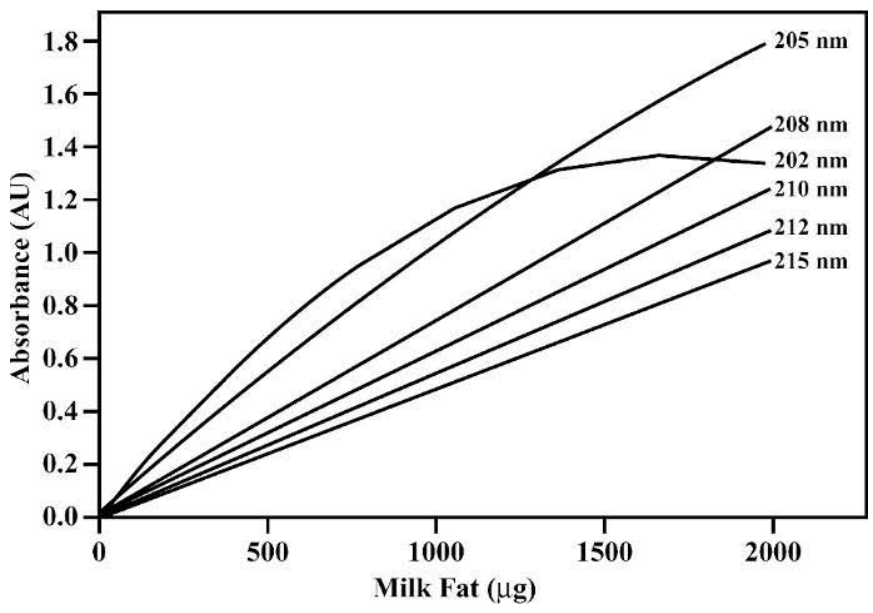

Figure 1. A) Ultraviolet spectrum of milk samples with different milk fat content in absolute ethanol. Note the peak shift at higher fat concentrations. B) Ultraviolet absorbance at various wavelengths of milk samples with different fat contents. To assess the most suitable wavelength for milk fat measurement, several milk samples with different fat contents were evaluated by the UV method, and their absorbances at various wavelengths were plotted. $\mathrm{AU}=$ arbitrary unit.

that corresponds mainly to naturally occurring conjugated dienes (Hamilton and Cast, 1999) and a sharp absorption peak in the range of $\sim 202$ to $215 \mathrm{~nm}$ that depends linearly on total lipid concentration (Gunstone et al., 1994), as previously reported for phosphatidyl choline (Klein, 1970). As can be observed from Figure 1A, the absorption peak of lipids shifts toward a higher wavelength $(\lambda)$ when milk fat content increases, so it was necessary to identify a wavelength that followed the Lambert and Beer law independently of the amount of milk fat present in the sample. 


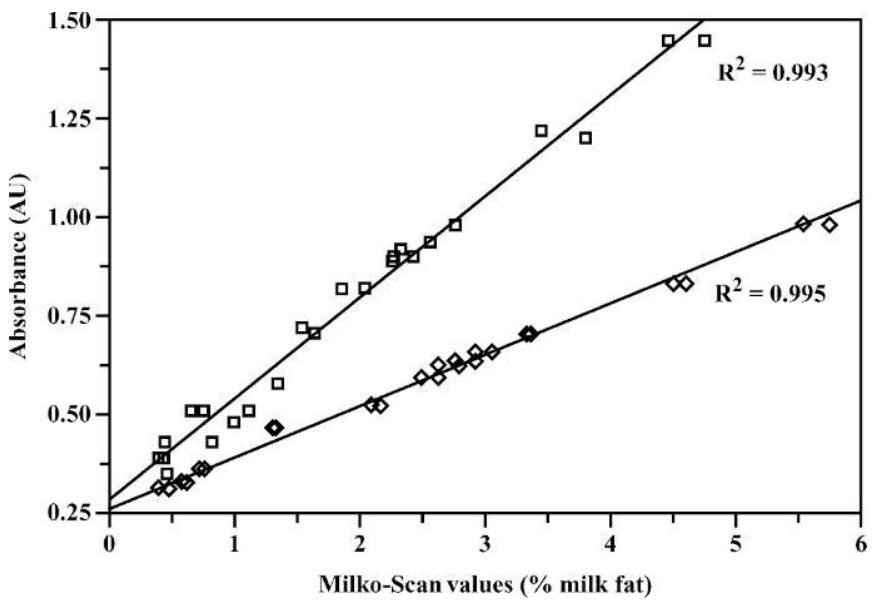

Figure 2. Correlation curves between Milko-Scan equipment and the UV method. Data from experiment 1 from laboratory 1 and experiment 1 from laboratory 2 were performed using $30 \mu \mathrm{L}$ of sample $(\diamond)$. Experiment 3 (laboratory 1 ) and experiment 2 (laboratory 2) were performed with $60 \mu \mathrm{L}$ of sample ( $\square$ ) and were analyzed together. $\mathrm{AU}=$ arbitrary unit.

In Figure 1B, absorbance vs. fluid milk fat content is plotted for several wavelengths. Even though linearity is observed for a wide range of wavelengths (from 208 to $215 \mathrm{~nm}$ ), sensitivity decays at higher wavelength as a consequence of lower molar absorptivity $(\varepsilon)$. Another drawback of using a wavelength $>215 \mathrm{~nm}$ is the overlapping of oxidized lipid (conjugated dienes) absorption, which could influence lipid measurement (Recknagel and Glende, 1984; Forcato et al., 2002). Thus, $208 \mathrm{~nm}$ was chosen as the measurement wavelength, although 210-, 212-, and 215-nm wavelengths are roughly equally suitable for milk fat determinations. A calibration curve using powdered milk was also performed, showing the same overall performance as the fluid milk calibration curve $\left(\mathrm{r}^{2}=0.986\right.$; data not shown).

\section{Correlation Between Milko-Scan Assay and UV Measurements}

A correlation study was performed between data from the Milko-Scan assay and the UV method from 5 separate experiments from 2 laboratories. Linear regression analysis showed a significant agreement between these methods (Table 1; Figure 2) in both laboratories using 30 and $60 \mu \mathrm{L}$ of milk sample as an assay fraction, although a better sensitivity (linear regression slope closer to 1 ) was achieved with an assay fraction of $60 \mu \mathrm{L}$ (Figure 2).

\section{Milk Fat Recovery Assay}

To assess the accuracy of the UV method, a milk fat recovery assay was performed. Ten sets of triplicate
Table 2. Milk fat recovery assay.

\begin{tabular}{lcr}
\hline & \multicolumn{2}{c}{ \% Milk fat recovery } \\
\cline { 2 - 3 } Milk fat content $^{1}$ & Milko-Scan $\pm \mathrm{SD}$ & UV method $\pm \mathrm{SD}$ \\
\hline $0.60 \mathrm{~g} / 100 \mathrm{~mL}$ & $80.9 \pm 0.9$ & $92.1 \pm 0.9$ \\
$1.00 \mathrm{~g} / 100 \mathrm{~mL}$ & $89.1 \pm 0.3$ & $110.4 \pm 1.2$ \\
$1.50 \mathrm{~g} / 100 \mathrm{~mL}$ & $87.0 \pm 0.3$ & $102.8 \pm 0.8$ \\
$1.80 \mathrm{~g} / 100 \mathrm{~mL}$ & $88.4 \pm 0.4$ & $116.8 \pm 1.5$ \\
$2.20 \mathrm{~g} / 100 \mathrm{~mL}$ & $88.2 \pm 0.5$ & $103.5 \pm 0.5$ \\
$2.60 \mathrm{~g} / 100 \mathrm{~mL}$ & $87.1 \pm 0.6$ & $97.2 \pm 0.4$ \\
$3.00 \mathrm{~g} / 100 \mathrm{~mL}$ & $86.5 \pm 0.8$ & $111.4 \pm 0.9$ \\
$3.50 \mathrm{~g} / 100 \mathrm{~mL}$ & $102.1 \pm 1.1$ & $98.3 \pm 0.4$ \\
$3.90 \mathrm{~g} / 100 \mathrm{~mL}$ & $98.4 \pm 0.2$ & $101.0 \pm 0.4$ \\
$4.30 \mathrm{~g} / 100 \mathrm{~mL}$ & $98.1 \pm 0.2$ & $97.8 \pm 0.4$ \\
Mean & $90.6 \pm 6.7$ & $103.1 \pm 7.6$ \\
\hline
\end{tabular}

${ }^{1}$ Milk fat was added to skimmed milk $(0.01 \%$ milk fat $)$ and whole milk ( $3 \%$ milk fat) to obtain different milk fat values. Percentages of recoveries are averages of 3 samples.

samples were increased up to different concentrations by adding milk fat directly to defatted and whole milk samples and were measured with Milko-Scan equipment and by the UV method. As can be observed in Table 2, Milko-Scan showed poor recovery (between 11 and $20 \%$ less fat than actual content) at low fat concentrations, probably because of calibration in the range of 3\% fat. The UV method showed a significant agreement with low fat samples, with only 3 recoveries exceeding $10 \%$. Recoveries for both methods were very good for normal and high fat content samples, but, because of the lack of accuracy of Milko-Scan for low fat content samples, mean recovery was better for the UV method.

\section{Precision of the UV Method}

To evaluate the precision of this method, 2 sets of 9 replicates of whole milk and skimmed milk were analyzed at 208, 210, 212, and $215 \mathrm{~nm}$. Raw data was subjected to ANOVA analysis (Table 3 ). The percentage of relative standard deviation (\%RSD) was acceptable for all wavelengths in both sets, with an overall $\%$ RSD of $3.79 \pm 0.12$ for the samples with higher fat content and an overall \%RSD of $4.88 \pm 0.16$ for lower fat samples. Average values of both sets of replicates at 208,210 , and $212 \mathrm{~nm}$ were not significantly different from reference values, although average values obtained at $215 \mathrm{~nm}$ differed significantly from reference values (Table 3 ).

\section{CONCLUSIONS}

Here we present a simple, economical method to measure fat content in fluid and powdered milk samples without prior extraction. This method makes use of the UV absorption properties of lipids that is propor- 
Table 3. Precision data for UV method.

\begin{tabular}{|c|c|c|c|c|}
\hline \multirow{2}{*}{$\begin{array}{l}\text { Sample milk fat } \\
\text { (reference } \\
\text { value) }\end{array}$} & \multicolumn{4}{|c|}{ UV wavelength of measurement } \\
\hline & $208 \mathrm{~nm}$ & $210 \mathrm{~nm}$ & $212 \mathrm{~nm}$ & $215 \mathrm{~nm}$ \\
\hline & & - & 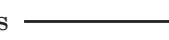 & 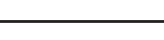 \\
\hline \multicolumn{5}{|l|}{$1.80 \mathrm{mg} / 60 \mu \mathrm{L}$} \\
\hline Mean & $1.79 \pm 0.06$ & $1.75 \pm 0.07$ & $1.84 \pm 0.07$ & $1.67 \pm 0.06$ \\
\hline$\% \mathrm{RSD}^{1}$ & 3.62 & 3.87 & 3.87 & 3.80 \\
\hline$P$ & $\mathrm{NS}^{\mathrm{a}}$ & $\mathrm{NS}^{\mathrm{b}}$ & $\mathrm{NS}^{\mathrm{c}}$ & $\mathrm{SD}^{2}$ \\
\hline \multicolumn{5}{|l|}{$1.15 \mathrm{mg} / 60 \mu \mathrm{L}$} \\
\hline Mean & $1.16 \pm 0.05$ & $1.13 \pm 0.05$ & $1.17 \pm 0.06$ & $1.03 \pm 0.05$ \\
\hline$\% \mathrm{RSD}$ & 4.70 & 4.79 & 5.02 & 5.02 \\
\hline$P$ & $\mathrm{NS}^{\mathrm{a}}$ & $\mathrm{NS}^{\mathrm{a}}$ & $\mathrm{NS}^{\mathrm{a}}$ & SD \\
\hline
\end{tabular}

${ }^{1} \% \mathrm{RSD}=$ Percentage of relative standard deviation.

${ }^{2} \mathrm{SD}=$ Media obtained is significantly different from reference value.

${ }^{a}$ Media obtained is not significantly different from reference value $(P>0.0010)$.

${ }^{b}$ Media obtained is not significantly different from reference value $(P>0.1)$.

${ }^{\mathrm{c}}$ Media obtained is not significantly different from reference value $(P>0.2)$.

tional to its concentration in the range of 208 to 215 $\mathrm{nm}$. The UV method correlated very well with MilkoScan fat measures $\left(\mathrm{r}^{2}>0.982 ; P<0.001\right)$, which uses equipment standard in the industry. Accuracy and precision were also acceptable, with a mean recovery percentage of $103.1 \pm 7.6 \mathrm{SD}(\mathrm{n}=30)$ and $\% \mathrm{RSD} \leq 5$ for the replicate assays.

\section{ACKNOWLEDGMENTS}

This research was supported by grants from Agencia Córdoba Ciencia, Agencia Nacional de Promoción Científica y Tecnológica (FONCYT), and Secretaría de Ciencia y Técnica-Universidad Nacional de Córdoba. The authors thank La Lácteo S.A for the use of MilkoScan equipment and Ing. Sergio Fernandez and Bioq. Claudio Gottero for their assistance. The authors also thank A. Mangeaud for his statistical support.

\section{REFERENCES}

Application Note, Dionex 345 1999. Extraction of fats from dairy products (cheese, butter, liquid milks) using accelerated solvent extraction (ASE). Dionex Corp., Sunnyvale, CA.

Forcato, D. O., R. P. Pécora, and S. C. Kivatinitz. 2002. Conjugated diene generation in thermically processed milk. BIOCELL Supplement III 26:76.

Gunstone, F. D., J. L. Hardwood, and F. B. Padley. 1994. The Lipid Handbook. 2nd ed. Chapman \& Hall, London, UK.

Hamilton, R. J., and J. Cast. 1999. Chemistry and Technology of Oils and Fats. 15th ed. Sheffield Academic Press, Sheffield, UK.

International Dairy Federation. 1987. Milk. Determination of fat content-Röse Gottlieb gravimetric method (reference method). IDF (FIL-IDF standard 1C), Brussels, Belgium.

International Dairy Federation. 1991. Milk and milk products - Fat content. General guidance on the use of butyrometric methods. IDF (FIL-IDF standard 52), Brussels, Belgium.

Klein, R. A. 1970. The detection of oxidation in liposome preparations. Biochim. Biophys. Acta 210:486-489.

Recknagel, R. O., and E. A. Glende, Jr. 1984. Spectrophotometric detection of lipid conjugated dienes. Met. Enzimology 105:331-337.

Smedes, F. 1999. Determination of total lipid using non-chlorinated solvents. Analyst 124:1711-1718.

Wüst, E., and L. Rudzik. 2003. The use of infrared spectroscopy in the dairy industry. J. Mol. Struct. 661:291-298. 